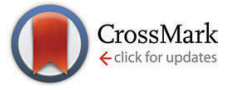

Cite this: Phys. Chem. Chem. Phys., 2016, 18, 13718

DOI: $10.1039 / c 6 c p 90114 j$

www.rsc.org/pccp

\section{Correction: On the stability of manganese tris( $\beta$-diketonate) complexes as redox mediators in DSSCs}

\author{
Stefano Carli, ${ }^{a}$ Elisabetta Benazzi, ${ }^{a}$ Laura Casarin, ${ }^{a}$ Tatiana Bernardi, ${ }^{a}$

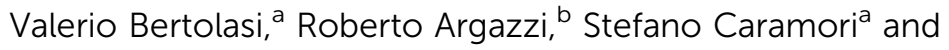 \\ Carlo Alberto Bignozzi*a
}

Correction for 'On the stability of manganese tris( $\beta$-diketonate) complexes as redox mediators in DSSCs' by Stefano Carli et al., Phys. Chem. Chem. Phys., 2016, 18, 5949-5956.

The authors would like to add the following Acknowledgments to their article:

"UNIFE gratefully acknowledges funding from Italian Ministry of Education (MIUR) PRIN 2010-2011 project."

The Royal Society of Chemistry apologises for these errors and any consequent inconvenience to authors and readers.

\footnotetext{
${ }^{a}$ Department of Chemical and Pharmaceutical Sciences of the University of Ferrara, Via Fossato di Mortara 17-27, 44121, Ferrara, Italy. E-mail: crlsfn@unife.it, g4s@unife.it

${ }^{b}$ CNR-ISOF c/o Department of Chemical and Pharmaceutical Sciences of the University of Ferrara, Via Fossato di Mortara 17-27, 44121, Ferrara, Italy
} 